\title{
Reflections on Teaching Human-Computer Interaction to Blind Students
}

\author{
Teresa Chambel, Pedro Antunes, Carlos Duarte, Luís Carriço, Nuno \\ Guimarães \\ University of Lisbon \\ DI, Faculdade de Ciências, Edifício C6, Piso 3 \\ Campo Grande, 1749-016 Lisboa, Portugal \\ $\{$ tc,paa,cad,lmc,nmg\}@di.fc.ul.pt \\ WWW home page: http://www.di.fc.ul.pt/ \{tc,paa,cad,lmc,nmg $\}$
}

\begin{abstract}
What challenges and opportunities do we face when we are to teach HCI to blind students, especially among sighted students, and having HCI curricula a traditional strong focus on visual aspects? How do you bring accessibility to learning and teaching a course that itself addresses accessibility? These are a couple of the questions we raised when faced with this challenge. This paper presents our experience, feedback and reflection on the subject, after two cycles of the course with blind students.
\end{abstract}

\section{Introduction}

Perception, interaction and accessibility are core issues in human-computer interaction (HCI), which have been researched and taught for some years now. But in 2006 we were faced with a new challenge that necessitated us to rethink and expand our educational methods for HCI: we had two blind students among a population of almost two hundred HCI students. At that stage we have already done research on accessibility, taught many HCI students, and some of us had already taught these, and other blind students, in other computer science courses. However teaching HCI to blind students appeared to be different from teaching other computer science subjects to blind students. But how were it different? In what ways? How should we approach the teaching? These questions motivated us, leading us to face the challenge. This paper reports on our experiences after two cycles of the course with blind students as part of the HCI group. Our main focus is on the first cycle, but we will also comment on the results of the second one. 
In the more than twenty years of computer science and informatics engineering teaching in our department, there was never a blind student until about six year ago: a girl, and around the same time, a visually impaired boy. Both of them successfully completed some courses, a couple of them in computer science, but left before the HCI course. The girl already held a diploma in education and she started working in a special school for blind people, teaching them how to use computers. The boy decided to graduate in statistics instead, which he already did successfully. The new blind students, another girl and boy, joined us three and a half and two and a half years ago, respectively. After teaching them three other courses ourselves, why would HCI be a different challenge? The first answer popping up was its traditional strong focus in visual aspects, and in particular the nature of the project students used to do. The second was that accessibility - the problem we were facing - is in fact one of the topics addressed in HCI.

So how do you bring accessibility to learning and teaching a course that itself addresses accessibility? Maybe the answer was inside, and while answering this question, we might also contribute to the course itself.

In trying to answer these questions, more specific ones appeared:

1. What challenges and opportunities do we face when we are to teach blind students, especially among sighted students?

2. How does blindness differ from other disabilities? Is it related with blind people cognitive models, their references from the outside world, their memories if they ever had the chance to see? How do they deal with space, fonts, colour, etc?

How should we approach teaching them?

1. Contents: should we teach them the same contents - in theory, practice and laboratories? If not, how should they differ? What are the easiest and more difficult topics for them to learn?

2. Access and Presentation: How to make information accessible? Should we explore different modalities and devices (e.g. Braille lines, screen readers, Digital Talking Books, 3D tactile models of diagrams and screens)? Should we present information in a different way, different analogies, explain it further?

3. Evaluation: should it be different, in what ways? In the project and or the exam? Individual or group projects? Involving blind students only or also sighted students?

4. Are these challenges analogous to those present in other computer science courses or specific to HCI? Does HCI hold a different kind of social, professional and humanitarian responsibility? Does it have the means to make a particular contribution?

Information and communication technologies provide us with key elements to facilitate social inclusion, and HCI addresses ways to approach it, sometimes with the goal of universal design [1]. In the context of HCI teaching, we believe these aspects are to be addressed at two levels:

1. Making HCI learning accessible to blind students;

2. Increase accessibility awareness in HCI, with the help of blind students.

Our search for literature in this area did not result in many hits. There is scarcely any literature focusing this specific topic of teaching HCI to blind students. This was 
also the experience of Prof. Tony Stockman from Queen Mary, University of London, who we came to meet recently in this process and who we will introduce later in the paper. This is probably due, in his opinion, to the small number of blind individuals that appear in these courses, every few years; so there is often no documentation of best practice or even of what does or does not appear to work. Also from our experience at the university, we do not get a special training for these cases, and even with some support from the Services for Students with Special Needs, the approaches we tend to adopt are somehow general, taking into account the means to make different types of content in books and slides accessible to the students, also providing students with general purpose access equipment like Braille lines and screen readers, and a few guidelines for type of explanations, extra time to answer exams, and lots of common sense and personal commitment in trying to reach them. Therefore, we did not have anything specific to teaching these students HCI.

So we tried to make our best. In the first year, we integrated them with the others in classes, and defined a special project that involved these two blind students and four other students, since we believed the regular project to be the less accessible aspect in the mainstream course. In the second year, we had one of these blind students again, and based on previous experience we decided to have her doing the mainstream course as a complement to what she had done the previous year. Although we received very positive feedback from the students, we wanted to explore the topic further, learn from previous experiences and guidelines that would help us to better understand the problem, and to compare them with what we were doing, helping us to reflect about our experience and conclude what went well and what could be improved in the future. In the absence of closely related literature, we broadened our search to include: learning styles and abilities, general aspects of teaching blind students, teaching $\mathrm{HCI}$ to students with cognitive disabilities, accessibility, also in HCI, multimodality, different types of interfaces, legislation, recommendations, and ethical issues.

In the next section, we present the most relevant related topics. Section 3 describes our experience. Feedback and our own reflections are discussed on section 4. The paper ends with main conclusions and perspectives for future work.

\section{Accessibility in Human-Computer Interaction Education}

Accessibility raises many challenges relevant to HCI. We present and discuss some of them, concerning ethical issues, and accessibility aspects both in learning HCI and as a topic in HCI curricula.

\subsection{Ethics in HCI Practice, Research and Teaching}

According to Mankoff [2], the discipline of ethics provides an important critical perspective that can positively influence the research, practice and teaching of Human Computer Interaction. The understanding of its imperatives like beneficence, respect for persons, and justice, must be a part of the scientific process of finding a 
solution to applied scientific problems. As service providers, there is a natural tendency to help the customer to know what is the best way to meet their goals (beneficence) and give them freedom of choice in the solutions we hand them (respect for persons). Standard curriculum implicitly addresses these issues. Justice is not so obvious and leads to issues of inclusion, such as fairness or equity in access to technology; being accessibility to people with disabilities an instance of this aspect.

In HCI teaching, this manifests itself in two situations: (1) making HCI learning accessible to people with various abilities; and (2) teaching accessibility aspects to every HCI student.

According to Mankoff [2], an HCI student must learn: a) to understand that as designers, they have a huge amount of control over who has access to the technology they produce - thus practitioners effectively define who is disabled with respect to their products; b) that not all forms of inclusion are just, because they may just lead to inequality at a different level. Too limited time spent on this lesson of accessibility and assistive technology can lead to misguided ideals. One bias is the usual tendency to seek out those who are like oneself as designers, something that can be attacked by an extra effort in knowing the target audience and using techniques such as contextual inquiry [3].

\subsection{Making HCI Learning Accessible}

The major challenge facing visually impaired students in the educational environment is the overwhelming mass of visual material to which they are continually exposed in textbooks, class outlines, class schedules, chalkboards writing, etc. [4]. In addition, the increased usage of videotapes, computers, and television adds to the volume of visual material to which they have only limited access.

Overcoming a students' visual limitation requires unique and individual strategies based on that student's particular visual impairment and his/her skill of communication (e.g., Braille, speed listening, etc.). The majority of people who are blind have some useful sight even if it is light perception. There is a great variety of sight loss, including blurred and cloudy vision; vision obscured by dark patches; restriction of the field of vision causing tunnel vision or the presence of peripheral vision only. Therefore, visually impaired people do not all 'see' in the same way, so we may have to adapt our teaching accordingly. Although 'visually impaired' is sometimes considered a more politically acceptable term, we chose to use the term 'blind' throughout the paper for clarifying purposes, since we are dealing mostly with people who have no sight at all. In the literature about differences between congenitally blind people and people who lost sight later in life, there is a tendency to assume that these cope better with blindness than those who were born blind, since they have more references and memories. However, this does not match everybody's experience. For example, Prof. Tony Stockman, who has been blind from birth and attended special schools, reports that his experience supports just the opposite; except maybe in some areas, like in understanding descriptions and perspectives of $3 \mathrm{D}$ buildings or structures. 
Dix [5] believes we are all aware of the importance of catering for physical disability and perceptual disability, like colour blindness, both in the HCI we teach and in the way we teach it (although not always so sure about how to approach it), but not so much aware for cognitive disabilities. In this context, until a couple of years ago, dyslexia was the only cognitive disability he had ever considered. The Asperger's Syndrome, related to autism, and Williams Syndrome, an 'opposite' condition, came to draw his attention, because they are relatively common amongst university computing students. Actually, Asperger's are often high attainers. Although with a few exceptions, documents and studies about cognitive disabilities at university levels also appear to be rare. Some of the practices to accommodate students with special needs are often good practice and benefit other students as well $[5,6]$, but that is not always the case. For example, redundant visual cues are good general HCI advice, but a thorough description of a diagram can become dull for a sighted person, beyond a certain level of detail, while of the utmost importance for a blind person to understand it. With regards to website accessibility, Hudson et al. [7] suggest that cognitive disabilities should be accounted for in page presentation and navigation, allowing the users to control presentation and content according to their needs.

Perhaps, the term cognitive 'disability' is sometimes abusively used for a 'different' way of learning. For example, Asperger's excel in technical areas, details, and learning rules, although not in learning facts. Blind people also tend to develop other perceptual abilities. Different cognitive styles [8] are more effective in some areas than others, they require different support, but somehow determine our best ways of learning. This is something we have to keep in mind, first as learners but then especially as teachers, if we want to reach and help our students to learn better. Blind students also present different styles of learning, although in what concerns perceptual styles, they have a tendency to be more audible, and sometimes kinaesthetic in regard to touch. So, different strategies should also be tailored to the different individuals.

\subsection{Teaching Accessibility in HCI Curricula}

Accessibility aspects, such as the design for disabled and elderly users, are increasingly important topics in the HCI curriculum, as inclusive design and assistive technology, also due to equality legislative requirements [6].

'Know thy users' is a common motto in HCI '...for they are not you', many would add [6]. It is important that students become aware of the existence of people with different characteristics, sometimes very different and some considered disabilities, and their needs; and learn how to design and evaluate systems that meet these needs. Both goals promote awareness to design for these users.

An HCI course could be designed around these topics, or use these examples as good illustrations in most concepts: eliciting user requirements, considering alternative imaginative designs, multimodality, interaction devices, personalization, and evaluation. Topics that Petrie et al. [6] recommend should be covered include: relevant legislation and legal responsibilities; characteristics of disabilities, ageing, and also, for instance, children, speakers of different languages and from different 
cultures; how these people use current technologies; and inclusive design as a design methodology, although difficult to teach in practice, discussion on how to achieve this may be most valuable. As best practices, Petrie et al. [6] recommend HCI teachers to: get some training in disability awareness; bring assistive technology to life in HCI classes and if possible to get a user of assistive technology, for e.g. a blind person, to give a demonstration of their practices; include a requirement for accessibility and inclusive design in any design exercises that they set. And finally, to turn accessibility into a positive intellectual challenge: it is more difficult but also more intellectually satisfying, stretching students further.

\section{Our Experience}

The HCI course at the Faculty of Sciences of the University of Lisbon is part of the 4th semester in the undergraduate Informatics Engineering curriculum. In the first course cycle with blind students, the central case reported in this paper, we had 188 students attending the course, among which, 2 were blind. We intended to accommodate these students the best we could, but also had a large population of other students to consider.

\subsection{Classes and Evaluation}

Based on previous experience with blind students, we decided to integrate these two students in the regular classes, encompassing theoretical and practical lectures as well as a few laboratory sessions. They attended the same lectures and were taught the same materials. Slides were made available in text format, with significant limitations due to the large number of graphical contents that could not be transcribed in an automatic way. Some extra attention could be given to these students in practical and laboratory classes, and sometimes extra time was necessary to provide additional explanations, trying to match the topics covered to their mental models on these concepts.

Regarding evaluation, we followed a different strategy. While the blind students had to answer a quite similar exam, ensuring they would acquire similar basic concepts as regular students, they developed a different project where their perceptual skills were especially accounted for, since the regular project was heavily based on visual aspects.

\subsection{Project}

Both the mainstream and the special project were developed by groups of three students and followed the same underlying structure: requirement elicitation, design, development, and evaluation in more than one iteration, although with different emphasis and themes, and involved tasks both as designers and usability testers. 


\subsubsection{Mainstream Project}

Regular students had two main goals: first to design, develop and evaluate a website, exploring different design criteria and guidelines in an open and creative way; and second, to suggest incremental user-interface improvements to a commercial application (a VoIP communication tool). Students also had to develop a portfolio with the results from the different project phases. Students were faced with two types of tasks all along the project: as designers of their own projects, and as usability experts assessing the colleagues' projects. Regarding the later task, in the average, each group received and answered approximately 30 questionnaires (selected at random by the web site technology supporting the portfolio development) for usability evaluation at each design stage. Considering the website, three design stages were defined: (1) requirements analysis, concerning the identification of website target audience and functional and interface specification, taking design guidelines into account, and low-fidelity prototyping of three preliminary design alternatives; (2) high-fidelity prototyping, using HTML and JavaScript, followed by a usability evaluation using online questionnaires; and (3) prototype refinement, combining the data obtained from the questionnaires with additional user feedback from task analyses and interviews, followed by another usability evaluation. The improvements proposed for the VoIP application were also subject to a usability evaluation through online questionnaires. After accomplishing each step, each group would make a presentation about their work, before the class. This way, students could share their findings and accomplishments with the others, receive additional feedback from colleagues and teacher, and last but not least, exercise their presentation abilities and public speaking skills.

This mainstream project was considered inadequate to blind students, mostly because it had a strong visual emphasis that could hardly be experienced by them and consequently could lead to frustration and disengagement.

\subsubsection{Special Project}

The two blind students were integrated in two special groups, each one involving one blind and two sighted students. They also had two specific goals for the project, built around their own portfolio. First, they had to make a survey on non-visual user interfaces; and second, they worked on multimodal digital talking books (DTB), instead of the website. As with the website project, some emphasis was put on usability testing, although in the DTB case, a special focus was requested on the non-visual interactions and different types of tests [9] were explored. They also answered to other groups questionnaires (mostly with the sighted students, due to the visual nature of the prototypes) and had some colleagues interviewed in their usability tests. The project had two milestones, one after the survey and the other one after the DTB evaluation. These students also made their presentations before the class. This way, they could share their work with the colleagues, and also learn from the other projects. In addition, a paper [10] was written and presented at a national $\mathrm{HCI}$ conference, describing the concepts involved and the experiences of evaluating DTB with a non-visual focus conducted by the students. This challenge was announced from the beginning as an extra motivation for students to excel in their work. 
In the survey, the two groups explored different aspects of non-visual interaction, covering: hardware interfaces (Braille lines, keyboards, note takers, and printers, scanners with voice output, virtual touch mice, data gloves, gesture wrists, GPS with Braille pads and voice synthesizer, and wearable computers); software interfaces and applications (screen readers, voice synthesizers, digital talking books, and audio games); and accessibility guidelines, including $\mathrm{W} 3 \mathrm{C}$ recommendations. These topics were later complemented for the paper's related work [10].

The second project stage dealt with the usability evaluation of a DTB player. The students' work was integrated within a research project currently underway in our research group, aiming at the development of tools for ensuring access to literary content for the visually impaired community. From the early stages of the project, the students were provided with the most up to date version of the DTB player and given access to the usability laboratory facilities. The DTB player is an adaptive multimodal application, supporting visual and audio input and output. Audio input is available through speech recognition. Audio output is available through prerecordings of the books and speech synthesis of awareness mechanisms. Given the blind students experience with audio interfaces, their contribution was valuable to the application's development.

The work started with the study of usability evaluation techniques, leading to the decision of what techniques to employ during the tests. Each group designed two controlled experiments, involving a set of visual and non-visual tasks. Preparations for capturing the experiments with video cameras and screen capturing software were made.

The experiments started with a debriefing for introducing the participant to the application and background of the tests. Participants had a ten-minute period for familiarization with the DTB player. After this period, the participants executed a set of tasks, and, in the end, answered a questionnaire about the application. Prior to the experiments, each group did a preliminary evaluation of their test settings. A first run was made with the groups' elements and a second one with one element from the other group. These pre-tests allowed the identification and correction of several errors in the experiment design, both in the tasks and questionnaires. They also provided some training for the debriefing stage. Since all the participants in the experiments were sighted, and although they had some non-visual interaction situations to experiment, these pre-tests were particularly relevant, because they rendered the opportunity to thoroughly test the application and experiment design also with blind users. During the experiments, conducted under the supervision of elements of the research team, most of the activities were performed by the sighted students of the groups. The blind students were most active in the debriefing stage. Between these experiments, each group suggested improvements to the DTB player. Due to time and resource limitations, not all the suggestions were implemented in the new version of the application used in the second experiment. This resulted in the introduction of a new evaluation technique for the second experiment - the Wizard of $\mathrm{Oz}$ technique - to test the unimplemented suggested features, in general related to audio interaction. Fig. 1 presents two pictures taken during these tests: a) one sighted student is conducting the test; b) blind students are following one test with the help of a sighted student in note taking. 
Overall, these experiments resulted in twenty usability evaluation sessions. The participants, twelve male and eight female, were all students from the Faculty of Sciences of the University of Lisbon, from different courses and curricula. No participant was visually impaired. In order to evaluate the different features and usage possibilities, three different evaluation scenarios were considered: in the first scenario, all input and output modalities were available to the participants, which were free to choose how to interact with the application; in a second scenario, the only allowed input modality were voice commands, but the output was still done using visual and audio modalities; in the last scenario, the interaction was exclusively done through audio channels. In this way, it was possible to evaluate multiple usage scenarios and compare modalities.

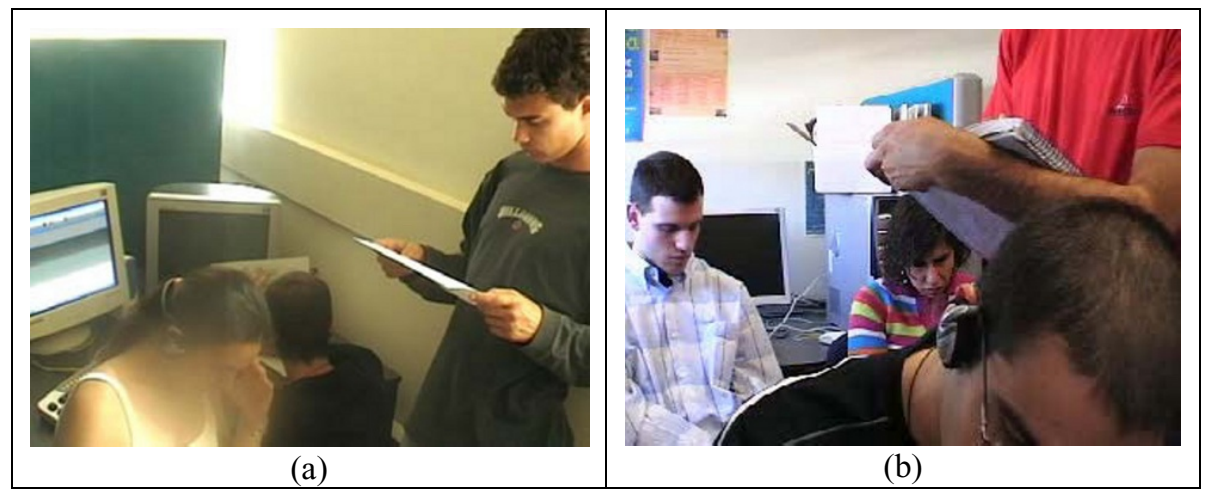

Fig. 1. Digital talking books usability tests

This one semester project gave the blind students the opportunity to experience the different design stages and to be involved in usability evaluation sessions, in addition to raising the awareness to the accessibility problems.

\section{Feedback and Discussion}

After the course and evaluation periods, the six students that participated in the special project were interviewed about their experience. In the process of reflecting upon this experience, we also discussed some topics with Prof. Tony Stockman, from the Queen Mary University London, who provided us with invaluable insights based on his own experience as an HCI blind learner and teacher. He has 18 years of experience teaching Computer Science topics, including 7 teaching HCI at a wide range of levels, although he never had any blind student. He led the HCI group at Staffordshire University for 3 years. His main area of research is the design of auditory displays, mainly for improving the accessibility of spreadsheets, providing overviews of interfaces and data, and supporting the analysis of physiological signals. 
In this section, we present the main feedback we received and discuss our experience in the light of related experiences and work.

\subsection{Students Profiles}

The students were aged between 20 and 25, four of which where sighted males and two blind: one male and one female.

One of the blind students (A) suffers from a rare condition of the genetic Alström Syndrome, in face of which she had a severe reduced sight as a child, and completely lost her sight at the age of 15 . Before completely loosing sight, she could read amplified text, and occasionally used computers, mainly for text processing. She remembers some colours are brighter or darker than others, and sometimes was able to identify some of them, especially after being told, but never mastered this visual property. She remembers many spatial objects and shapes. Currently, she uses screen readers and a Braille line, which she got from the Faculty, and a Braille printer at the faculty library.

The other student (B) is blind since birth due to complications, damaging the optical nerves, resulting from his premature birth at 6.5 months and permanence at an incubator. He has developed the shape and space concepts, perceived mainly through touch and moving around. He knows colour is a visual attribute of objects, but he is not sure how it manifests, being different from texture for example, something he can partially perceive by touch. He was also not familiar with the concept of font, but this one is easier to grasp from touch. Although he never saw, he has a very good spatial orientation, especially in places he knows well. Currently he uses screen readers, a Braille line and a printer. He already used these before coming to the Faculty, bought with social security funds. However, he got a more modern Braille line and a portable PC from the Faculty. Both of them never had contact with more sophisticated devices, like data gloves or 3D mice.

In the first year reported, all but one of the students, a sighted one, were taking the course for the first time. All students completed the project successfully, but only half were successful in the exams: blind student B and two of the others, not all from the same group. One of them never even tried due to some personal matters during the exams seasons. In this year, the second cycle of the course with blind students, student A completed the course successfully.

\subsection{Contents Covered in the Course}

Most of the students said it was a good idea to learn the same contents. In particular, both blind students found it useful and interesting to learn the same contents, because it is important to know what other colleagues in the area know, if they are to integrate the same professional environments. This is true even if they have an extra challenge dealing with the more visual aspects, and against some of the sighted colleagues opinion: 'I believe some of the topics are not understandable, superfluous or even useless to them.'

Most of the topics were considered understandable to the blind students. They commented they found some of the other courses more difficult, e.g. Operating 
Systems. Being the biggest challenge the understanding of visual design issues, most of which they did not have to really deal with as they made a different project. This goes inline with Prof. Tony Stockman experience: 'I personally find HCI relatively straightforward [compared to other computer science courses] in terms of a typical undergraduate or postgraduate curriculum, of course advanced research papers take some reading and digesting as in any field. [...] I think colours and fonts are tricky because they are not something for which there is a clear equivalent for a blind person. [...] If someone has seen and was old enough to know the names of colours then [the concept is understandable]. To someone who has never seen, like myself, I guess I tend to think of colour a bit like being equivalent to timbre in sound, i.e. there are infinite numbers of possibilities, that it very much helps to form one's impression of the thing you are looking at and, like timbre, it is also possible to have things of very nearly the same colour or very widely differing colour. Also, because colour is so heavily used in our everyday vocabulary, blind people are very capable of understanding and using commonly used colour-based phrases, such as 'as black as night', 'green with envy', 'as pale as a ghost' etc. [...] I think layout is more tangible because some of the rules of good layout: consistency, simplicity, affordance etc. are equally applicable to Braille or auditory displays.'

In another perspective, finding some other courses more difficult also matches what Edwards et al. [11] perceive in Computer Science students, as they tend to consider HCI easy and somehow common sense, although not always being very successful at mastering it. Computer Science students tend to get satisfaction in studying a topic which is hard to understand but which becomes clear with time and effort, leading to an awareness of a level of mastery; whereas HCI requires a more open arts-like attitude, where sometimes there is no right answer. It is less deterministic, involving more subjective aspects, like human factors and design. Focus on analyzing and criticizing existing systems and using other student's designs, as well as focusing on the design process, are suggested approaches to improve effectiveness in HCI learning by Computer Science students. Our own approach matches most of these recommendations, and in particular for the blind students, more subjective issues somehow tended to be less central, since they tended to focus on usability and efficacy rather than aesthetics and liking.

Besides the visual design, another topic that was found more complex by blind students was related with the engineering aspects of interactive systems architectures, especially toolkits and window systems. Student A simply did not study these topics, while student B did not give much attention to them, because he found them unclear, in his words 'not very practical, perceivable' so he decided to focus on the other topics. This observation was confirmed by looking retrospectively into the blind students' exams. While both students were able to articulate and explain several human-computer interaction theories, most descriptive topics related to user interface components and their relationships were wrongly explained or simply unanswered. In Prof. Tony Stockman's opinion, this is understandable due to lack of diagrams, but he believes 'also, this may not be a problem for younger people, having been brought up with procedural models of programming, [but] I found descriptions of event-driven systems in some texts rather confusing, it is just an area where very clear writing makes all the difference.' 
This could mean that more technical-oriented courses on user interfaces would be harder for blind students than more broad courses on human-computer interaction, with more theoretical focus, or that better supporting materials were required. More evidence is needed. For example, Prof. Tony Stockman 'has not found any aspects of HCI that with some effort, and occasional assistance from a sighted person, that he was unable to internally visualize and appreciate. [...] The text copy of Alan's book [12] was extremely helpful with this.'

\subsection{Contents Accessibility and Presentation}

Students had access to a text version of the course slides, and student B recorded the classes, as he usually does in every course, often also making it available to student A. So they listen to the recorded tapes and use screen readers and a Braille line to access course contents. They found the content accessibility to be similar to what they are used to. The main difficulty, as usual, is dealing with images, and they would have benefited from the textual version of the textbook as well.

Regarding our behavior in classes, whenever a blind student was present, we entered a different mode of explaining the materials, something we trained over in the different courses we taught them, and is particularly difficult the first times. We provided more descriptive information, especially related with any available sketches and diagrams, sometimes reducing related and complementary information, and avoiding some common contextual references we would provide should we have the time. It is like a cognitive breakdown [13] that gets us to a mode where we become more aware of the process of explaining, and more reflective [14]. In this mode, we tend to explain some things differently, especially when in the presence of descriptive materials, such as diagrams or pictures. We explain them in more detail sometimes in a way that becomes too exhaustive for the rest of the audience, as many times was pointed out during lectures - tend to describe visual relationships that are obvious to the others, and make references to some things we think they are more familiar with. We try to find different examples or to explain the same examples in different ways. This however is difficult to do in very large classes, and sometimes we get distracted and get back to the more usual and somehow more experiential mode of explaining, until the next breakdown when attention is drawn back again to these students and how we are conveying the messages. In some cases, to make up for this, we tend to explain some topics further, after or outside the classes.

\subsection{Examination}

The exams given to the blind students were very similar to the other exams, with up to $10 \%$ different questions, addressing less visual aspects of interaction, or having additional explanations making up for the absence of figures. The blind students found the exams to be adequate, while still covering the wide range of topics. The student failing the exams blamed it mainly on the lack of study, and having to study also for other courses. One of the blind students suggested having two tests instead 
of a final exam, to reduce the amount of topics to study each time. However, the other student found it ok.

Blind students received their exams in digital text format on a portable PC. They wrote down their answers inline in the text file, having their screen readers and Braille lines helping in the access. They also had 50\% extra time to complete their exams, according to a special regulation, which has proven to be adequate in the cases we had so far.

\subsection{Project}

We will discuss aspects related with the project theme: Non-visual interfaces and multimodal Digital Talking Books, and the team work involving the two groups of three students.

\subsubsection{Theme}

All the students found it adequate to do this type of project, different from the mainstream, exploring non-visual interfaces. They found the survey very useful to broaden their perspective and knowledge on the field, and did enjoy studying and evaluating the DTB player, in a more practical perspective and related with a research project. Main comments: 'It was a very good theme', 'the survey and the DTB project complemented each other', 'it was a fine opportunity to participate in a research project, contacting other researchers and teachers outside the classroom, and to do the evaluation tests in a usability lab', 'it was a rare opportunity to learn something different', 'I felt useful sharing my experience with others that didn't know about non-visual interfaces'

The only drawback pointed out was that they were not learning and acquiring the same skills as the other students, although they could learn some of it from the colleagues' presentations and the few usability questionnaires they answered to. The blind students did not answer these questionnaires because they felt way too far from what they could easily perceive, and it was not a central issue in their own project. However, the students believed that they could more easily catch up with the missing knowledge on their own, than with what they learned in the other project in such special conditions.

In the end, they all felt more comfortable about designing a non-visual interface. Sighted students think they would be able to approach the design of a visual interface, while blind ones are not so sure: 'Maybe with some help, I could mange to build one. I might have something to say and contribute in such a design.'

Prof. Tony Stockman's experience reinforces this belief: 'I also have not found my blindness has stopped me from being able to make suggestions about how to improve the visual layout or design of things in some cases, providing of course I have a clear understanding of the task and the interface.'

\subsubsection{Team Work}

All students found it important to have both sighted and blind students in the group, and sharing experiences with the other group. They recognized as most significant contributions of the blind students the explanations about their interaction experiences: their challenges in traditional interfaces, their workarounds and special 
tools to cope with limitations, and their experience, feedback and informed suggestions in non-visual interaction. On the other way around, sighted students, helped in understanding visual aspects of the interfaces they encountered, even on the DTB, sometimes using analogies that they could understand, and dealing with more practical matters. For instance, they were usually faster in finding information on the web, although some topics were suggested by the blind students; more at ease in conducting other people in the interviews and usability tests; managing the videos to review the recorded interviews, especially to notice what the user was doing when comments were made or how the interface responded to a particular action; and found it easier to make slide presentations and to some extent also talk before the class. However, the blind students also talked to the class, showing them a Braille line and telling them about the interfaces they used.

\subsection{Research Paper and Conference}

Participating in a project that lead to a research paper was perceived as a very good experience by all the students. It motivated them to do better, had their work recognized, felt they had made a contribution to something that could reach other people, and could enrich their professional experience and curricula vitae. Only one of the blind students could manage to attend the conference. The students that did not participate regret it to some extent, but they had several restrictions, including tests and projects. Student A enjoyed attending the conference because she heard about interfaces she did not know possible, and became more aware of the topics researched in the field. She felt motivated to learn more about some of the topics as a future professional and for her own use.

\subsection{High and Low}

For the blind students, the best aspects of the course were related with the project: its theme, the contact with a recent type of application, cooperation among the team colleagues and usability tests. Not so good, were some topics in the course that were not so accessible to them, like visual design issues. As for the others, they liked mostly the new perspective of human-computer interaction. All of them would have chosen the same project, did they have the chance to be in the same situation again.

Most of them slightly regretted not learning some of the topics in the mainstream project, like some visual design aspects and gaining more practice on HTML and JavaScript, but overall it was a very good experience. To overcome this aspect, we encouraged them to build a personal home page on their own, an idea they welcomed.

Based on this finding, this year we had student A integrated in a group with two other sighted students, doing the mainstream project. She liked the experience, especially as a complement to last year's project, and could successfully complete the project with the colleagues. She claimed that she gained more awareness of the aspects that are relevant in visual interfaces, although she recognized that she does not master the subject. In the project, they also explored some accessibility aspects, 
including audio feedback; and student A improved her skills in webpage construction.

As a by-product of the collaboration among the students, sighted students recognized they gained accessibility awareness, increasing their understanding of other people's needs: 'it was a very enriching experience in human terms.' One of them told us he was already creating his own webpage, where he was taking accessibility issues into account, especially those concerning blind users.

\section{Conclusions and Perspectives}

Facing the challenge of teaching HCI to two blind students, among almost two hundred sighted ones, and in spite of our previous experience both as HCI researchers and teachers and as teachers of blind students in other computer science courses, motivated us to re-think and expand our educational approaches in this area. Somehow, this combination seems different, holding new problems and opportunities. In one hand, HCI has a traditional strong focus in visual aspects, and in the other, the problem we were facing - accessibility - is in fact one of the topics addressed in HCI. Maybe the answer was inside, and while answering this question, we might also contribute to the course itself.

Based on our previous experience with blind students, we decided to integrate these two students in the regular classes, encompassing theoretical and practical lectures and laboratory sessions; although we tried to adjust the way we taught whenever one of them was present. In some situations, we also provided additional explanations after or outside the classes. In the first year reported, they had access to a textual version of the slides and one of them recorded the classes in audiotapes making them available to the other one. Considering evaluation, the blind students had to answer a quite similar exam, ensuring they would acquire similar basic concepts as regular students, but developed a different project where their perceptual skills were especially accounted for, since the regular project was heavily based on visual aspects. This project had the same underlying components of user requirements, design, development and evaluation, but with different emphasis and flavor. It included a survey on non-visual interfaces and some work on multimodal digital talking books (DTB) with some emphasis on usability testing and non-visual interactions. The work on DTBs was integrated on a research project and lead to the publication of a paper on a national HCI conference. In the second year, the textbook was also available in digital text format, and the blind student $\mathrm{A}$, who was repeating the course, was again integrated in a group with two sighted students, but did the mainstream project this time.

In the process of reflecting on our experience, we interviewed the students involved in these special groups that integrated the blind students, and had the opportunity to share and discuss our experience with an HCI teacher who is himself blind. We also reviewed some related literature, to find there is scarcely any in this specific topic. But still, we addressed some related topics.

At this point, and in what concerns teaching blind students, we believe there are general aspects similar in every course where general purpose approaches do apply, 
and others specific to each course. We emphasized the ones we believe are most relevant in HCI, relating especially to visual aspects and accessibility, and raised a few question on how to approach this teaching accordingly.

Only having two blind students, and bearing in mind that there are many other factors influencing their attitudes and cognitive abilities other than their blindness, perceivable as different even in these two individuals, we tried not to jump into conclusions. However, based on our research and experience, which overall we found very positive, we believe we learned some lessons that allowed us to draw some conclusions and identify some open issues and directions for further research. These are presented next, in the context of main raised questions.

Contents: It was a good idea trying to teach them the same contents as much as possible. These students like to be treated the same way as other students and to become familiar with the same knowledge, even if they have to experience information in different ways. An open question remains on how far to go in this process, helping to expand their perceptual and cognitive limits. The answer will probably change with each individual. Visual properties and design guidelines were among the most inaccessible issues, but students still believe they would like to give it a try, should they have the adequate support.

Technical-oriented aspects of user interfaces seemed to be harder for our blind students than more broad and theoretical aspects on HCI, although not problematic for Prof. Tony Stockman, for instance. More evidence is needed to determine whether this is a structural issue, or if it only requires better supporting materials.

Access and Presentation: Blind people must have their specific perceptual abilities taken into account in order to be able to access the course materials (e.g. books, slides, classes). Some of them, and probably more if they are approaching HCI aspects, also appreciate means that help them to gain awareness or knowledge about the perception they lack.

Providing materials in text and recording classes do help them. However, although they were used to have a similar type of access to materials in other courses, and in consequence not complaining, some improvements can be made. Pictures and diagrams should be made available in an as much accessible format as possible. Prof. Tony Stockman defends that 'If blind students use either Braille or a screen reader, they will experience GUIs in a relatively serial way, and so diagrams should have value in at least conveying a two-dimensional idea of the layout [...] and screen design.'

Although some initiatives are starting this year, involving volunteer students, to describe pictures and diagrams in course material to make them accessible to blind students, this is an error prone and lengthy process, information is serialized, and some even lost. Other alternatives include tactile diagrams, drawn or printed in special sometimes expensive types of paper, and the use of 3D mice to access them online. These mice might also help them use graphical tools, which they currently do not use, sometimes adopting different descriptive approaches (e.g. a BNF based notation for Entity-Relationship modelling). Prof. Tony Stockman suggested that blind students might also find it useful to construct their own Braille-based representations of some techniques such as hierarchical task analysis, dialog design notations or user action notation. 
Digital talking books $[10,15]$ can also increase book accessibility to these students. Some recordings are also underway for a book and a couple of research papers, for this format, to make them accessible to the students. Somehow related, web lectures, in audio or in video [16], could support accessibility to classes, avoiding the students need to record the classes they attend, and improving flexibility and efficiency in storage and access methods, as well as the integration of these classes with other materials (slides, books, exercises, digital books, etc). The different materials and modalities would help to support different perceptual and learning styles. Diversity and flexibility would allow personalized tailoring of presentation and content.

This is still a problem in live classes though. How to make our presentations accessible to the diverse audience, especially when there is no balance, e.g. $1 \%$ $99 \%$ ? What is adequate for sighted students can be inaccessible to the blind, and what is adequate for the blind can be redundant and dull for the others. We tried to reach a balance in class and sometimes provided extra explanations to blind students after or outside the class - but it is not always effective, although there is an interesting side effect of having them all confronted with the others point of view, increasing accessibility awareness. Another direction to exploit here is aligned with the general tendency of delivering studying materials online, where personalized access is also easier, leaving face-to-face classes the role to engage and motivate students to learn [17].

Probably due to recent advances in the field and to the small amount of blind students that enter the university, supporting services usually address general purpose approaches and do not have themselves access to most modern technology, especially in the recent years when technology is reaching more diverse audiences and accessibility became a priority in information society. Maybe this is another point where HCI people can contribute to the scenario.

Evaluation: Having comparable exams seemed a good choice, allowing to evaluate similar kinds of knowledge, although blind students usually take more time to answer, something already covered by regulations. Joining blind and sighted students in the special project seemed to be a good approach. They had a very good collaboration, complementing each others in their skills, and sharing their different experiences and perspectives. Sighted students could perceive the difficulties blind users have with common interfaces, as well as the difficulties of designing interfaces that take their needs into account. Blind users brought an important contribution with their experience and suggestions. They also had the chance to explore more diverse and sophisticated evaluation methods in a usability laboratory, and to participate in a research project. The theme of the project was perceived as adequate by all, where their perceptual skills were especially accounted for, and allowed them all to learn more about an interesting topic. To some extent, students regretted not exploring further some of the topics in the mainstream project, although they learned part of it in classes and from colleagues' presentations. This was compensated for in the case of student A this second year, having her participating in the mainstream project. The special project in the first year required a significant amount of extra support from the teacher and a couple of colleagues from the research project, especially in the usability tests. We believe this context was enriching for the students, and in the process allowed for some research contributions, but it is not mandatory in providing 
blind students with a different project. Anyway, some extra effort might always be required to support these students in special projects.

Although it was a positive experience, an open question still remained: to what extent could we support these students doing the mainstream project and how effective and worthwhile would it be for them to try it?

From our experience in the second year, with student A repeating the course but doing the mainstream project, we got a positive outcome. It was especially so, being a complement to previous year's project. Although some aspects related to exploring different modalities to help her gain awareness of the perception she lacks could be further explored, it was a positive experience, encouraging more work in this direction.

HCI and Accessibility: We believe that, to some extent, this experience helped making HCI more accessible to blind students and also helped to increase accessibility awareness among sighted students, and even among teachers and researchers. This was definitely true in the two groups and partially in the practical and lab section these students belonged to - one in seven. We also had a practical class on creativity where students were encouraged to invent an application, make some sketching and present their product design to the class. Some are more conservative, some are more daring and futuristic. It was interesting to notice that in the blind students section, many designs accounted for speech interaction and auditory feedback. Blind students may contribute to enrich the learning scenario, and these ones welcomed the opportunity to share their experience with the colleagues, although they did not feel much comfortable talking in public. They also had the chance to learn more about different types of interaction, and especially more about non-visual interfaces. A further step might be taken in the direction of increasing students' perception about non-dominant perceptive abilities: to help blind people grasp what it is like to see, or a sighted person what it is like to be blind. Although having contributed to this aspect, accessibility awareness and support might have been explored further and to the widest audience, stressing that it is not exclusive to people with physical impairments but also relevant to people with temporary conditions or in special conditions of use [18]. Maybe we'll take this opportunity to increase our focus on accessibility in future cycles of the HCI course, even if we do not have students with special needs attending, as suggested by Petrie et.al.[6]. Finally, it is important to increase accessibility awareness among teachers, about their diverse learners and how to go about helping them to learn better. We hope to have contributed in this direction as well.

\section{Acknowledgments}

We would like to thank Prof. Tony Stockman from Queen Mary, University of London, for his invaluable testimony, and Prof. Alan Dix from Lancaster University for introducing us. Our thanks also go to the six students participating in the special project, Ana Catarina Rua, Eduardo Santos, Guilherme Francisco, João Robalo, Sérgio Neves, and Tiago Fernandes, for their feedback. We thank our Faculty for funding the Interacção'2006 conference participation of student A and 
accompanying colleague, and in particular Prof. Dulce Domingos, currently the responsible person for Students with Special Needs in our Department, who dealt with this process. We also thank Prof. Ana Paula Cláudio and Prof. Isabel Nunes, previously performing these same functions, who also had an important role in the support of our blind students in the last years. The DTB research work was partially funded by Fundação para a Ciência e Tecnologia in the project POSC/EIA/61042/2004.

\section{References}

1. E. Rodríguez, M. Domingo, J. Ribera, M. Hill, and L. Jardí, Usability for all: Towards improving the e-learning experience for visually impaired users. In Proceedings of ICCHP'2006 - Conference on Computers Helping People with Special Needs, Univ. of Linz, Austria, July 12-14, (2006).

2. J. Mankoff, Applying ethics to the practice, research, and teaching of Human Computer Interaction. Reflective HCI: Articulating a Research Agenda for Critical Practice Workshop at ACM CHI'2006, Montréal, Québec, Canada, 22-27, April (2006).

3. Beyer, H. \& Holtzblatt, K., Contextual Design: Defining Customer-Centered Systems. (San Francisco: Morgan Kaufmann Publishers, 1998).

4. Online Resources for Teaching Blind Students http://www.uni.edu/walsh/blindresources.html

5. A. Dix, The right mind? ACM SIGCHI Bulletin HCI Education column, Jan/Feb (2001).

6. H. Petrie, and A. Edwards, Inclusive design and assistive technology as part of the HCI curriculum. In Proceedings of HCI Educators Workshop'2006, Limerick, Ireland, 23-24 Marh, (2006).

7. R. Hudson, R. Weakly, and P. Firminger, An Accessibility Frontier: Cognitive disabilities and learning difficulties. In Proceedings of OZeWAI'2004, La Trobe University, Melbourne, Australia, December 2, (2004).

8. T. Chambel, and N. Guimarães, Learning Styles and Multiple Intelligences, Encyclopedia of Distance Learning, (Idea Group Inc., April 2005).

9. P.W. Jordan, Methods for Usability Evaluation. In An Introduction to Usability, pp. 51-80 (London - Bristol: Taylor \& Francis, 1998).

10.C. Duarte, T. Chambel, H. Simões, L. Carriço, E. Santos, G. Francisco, S. Neves, A.C. Rua, J. Robalo, and T. Fernandes, Avaliação de Interfaces Multimodais para Livros Falados Digitais com foco Não Visual. In Proceedings of Interacção'2006, Univ. do Minho, Braga, Portugal, 16-18 Outubro, (2006).

11.A. Edwards, P. Wright, and H. Petrie, HCI education: We are failing - why?. In Proceedings of HCI Educators Workshop'2006, Limerick, Ireland, 23-24 March, (2006).

12. A. Dix, J. Finlay, G. D. Abowd, and R. Beale, Human Computer Interaction. 3rd Edition, (Prentice Hall, 2003).

13.T. Winograd, F. Flores, Understanding Computers and Cognition: A New Foundation for Design (Addison-Wesley, 1986).

14.D. Norman, Things That Make Us Smart (Addison Wesley Publishing Company, 1993).

15.C. Duarte, T. Chambel, L. Carriço, N. Guimarães, and H. Simões, A Multimodal Interface for Digital Talking Books. In Proceedings of WWW/Internet'2003, iadis, Algarve, Portugal, 5-8 November (2003).

16. T. Chambel, C. Zahn, and M. Finke, Hypervideo and Cognition: Designing Video-Based Hypermedia for Individual Learning and Collaborative Knowledge Building, Chapter II, in 
Eshaa Alkalifa (ed), Cognitively Informed Systems: Utilizing Practical Approaches to Enrich Information Presentation and Transfer, (Idea Group Publishing, January 2006).

17. A. Dix, Deconstructing the experience of (e)learning for delivery ecologies. Talk given at The e-learning Experience, Birmigham Institute of Art and Design, 15th October (2003). www.comp.lancs.ac.uk/computing/users/dixa/talks/elearning2003

18. M.S. Gazzaniga, R.B. Ivry, and G.R. Mangun, Cognitive Neuroscience - the Biology of the Mind. (W. W. Norton \& Company, 1998). 